\title{
El ECOMUSEO COMO ESPACIO PARA LA ACTIVACIÓN DE PROCESOS DE GOBERNANZA TURÍSTICA. Cogestión DEL PATRIMONIO COMO GESTIÓN RESPONSABLE
}

\author{
Héctor Moreno Mendoza \\ hectormormen@gmail.com \\ Universidad de Las Palmas de Gran Canaria \\ Agustín Santana Talavera \\ asantana@ull.edu.es \\ Universidad de La Laguna
}

Un ecomuseo orienta sus tareas de conservación, formación y reproducción identitaria y patrimonial con base en la cercanía al territorio y a sus poblaciones. Ello conlleva un sistema de gestión flexible que se adapta a especificidades contextuales, empoderando a las poblaciones locales para gobernarse por sí mismas con relación a un proyecto común. Este estudio explora la activación en los procesos de gobernanza en los ecomuseos, en el Proyecto Cultural de Desarrollo Comunitario de la Aldea en la isla de Gran Canaria (Islas Canarias, España), conformado por 15 museos relacionados con oficios y labores tradicionales. A partir del análisis es posible confirmar que la cogestión, en concordancia con la gobernanza, es una herramienta eficaz para el reparto de responsabilidades y competencias en la gestión de los recursos, siendo sostenible en el tiempo y contribuyendo a superar crisis intermedias (económicas y sociales).

Palabras clave: antropología social, ecomuseo, gobernanza, gestión, Islas Canarias

\section{The Ecomuseum as a space for the Activation OF TOURISM GOVERNANCE PROCESSES. Heritage CO-MANAgement AS RESPONSIBLE MANAGEMENT}

An ecomuseum guides its conservation, training, and identity building and heritage reproduction, based on proximity to the territory and its populations. This entails a flexible management system that adapts to contextual specificities, empowering local populations to govern themselves in relation to a common project. This study explores the activation in ecomuseum governance processes, in particular The Cultural Community Development Project of the Village on the island of Gran Canaria (Canary Islands, Spain), consisting of 15 museums related to traditional crafts and work. From the analysis it is possible to confirm that co-management, in accordance with governance, is an effective tool for sharing responsibilities and competencies in resource management, being sustainable over time and contributing to overcoming intermediate crisis (economic and social).

Keywords: social anthropology, ecomuseum, governance, management, Canary Islands

Fecha de recepción: 16 de febrero de 2020. Fecha de aceptación: 14 de abril de 2020

CÓMO CITAR: Moreno-Mendoza, H. y Santana-Talavera A. (2020). El Ecomuseo como espacio para la activación de procesos de gobernanza turística. Cogestión del patrimonio como gestión responsable. Dimensiones Turísticas, 4(6), 9-38. https://doi.org/10.47557/ZCGR8597 


\section{Introducción}

a elevada oferta cultural que se ofrece como museos y otros activos culturales ha

hecho que estas instituciones desarrollen cada vez mejor sus capacidades para gestionar tanto retos medioambientales (Lebel et al., 2006; Lucchi, 2016) como sociales (Carbone, 2019). Una de estas respuestas ha sido la innovación en las formas de entender y definir los ecomuseos (Davis y Corsane, 2014, p. 119). Se entiende aquí que los ecomuseos se caracterizan por identificar, en una región dada, el ambiente de vida tradicional a través del patrimonio cultural y natural valorizados para ser protegidos y preservados (Elliot, 2006). En este sentido, y tomando como base la Declaración de Intenciones del Long Net Workshop, Trento Italia (Red Europea de Ecomuseos, 2004), el ecomuseo es aceptado como una forma de acuerdo dinámico comunitario (Taylor, 2020), por el que se preserva, interpreta y gestiona el patrimonio para un desarrollo sostenible.

Esos acuerdos son la base para la implantación de mecanismos de gobernanza, con el objetivo común del desarrollo social, medioambiental y económico de la población local. Ese proceso común de gestión en el patrimonio (Davis, 1997, p. 199) pasa por la responsabilidad entre los actores del recurso cultural, promoviendo múltiples usos del patrimonio. Entre ellos destaca el uso turístico, tomando la cultura y el entorno socioecológico como atractivo, en principio, para formas alternativas de turismo.

El turismo responsable se basa en el turismo sostenible, pero sin llegar a convertirse en una tipología turística específica o temática (Idelhadj, Rivera y Rodríguez, 2012). Más que un producto, se trata de una serie de compromisos, sensibilidades, y responsabilidades sobre las acciones que afectan tanto al turista como a los operadores e intermediarios turísticos y las administraciones públicas implicadas. Siguiendo estos principios, todos deben reconocer el papel central de la población local y el control que puede ejercer en los procesos de desarrollo turístico de su territorio (Santana-Talavera, 2008). Esta forma de concebir el turismo tiene una faceta social que implica respetar, promover y desarrollar las culturas locales y protegerlas de la homogeneización cultural, la sobrecomercialización y la sobreexplotación. Para ello, se promueve el control y la autogestión de los recursos locales por la participación de la comunidad local. Se utilizan así diferentes estructuras organizativas en el proceso de toma de decisiones (adaptadas a las especificidades de las poblaciones y sus territorios), buscando un reparto equitativo de los beneficios, el respeto y defensa de la cultura e identidad local, favoreciendo las vías hacia la sostenibilidad y el diálogo intercultural en el desarrollo turístico. 
El turismo responsable (TR), como acción turística vinculada al movimiento de los ecomuseos, constituye en sí mismo un movimiento social que involucra a un nicho de mercado (Reverté y Guix, 2013). La aplicación de tales acciones sobre un territorio, además de contribuir positivamente a la conservación del patrimonio natural y cultural, potencia experiencias memorables y mejor percepción de los lugares tanto para los anfitriones como para los visitantes. EI TR como actitud tiende a: minimizar los impactos socioculturales, socioeconómicos y ambientales no deseados, mejorar el bienestar de las poblaciones de acogida, involucrar a esas poblaciones en las decisiones que afectan sus vidas y oportunidades de futuro, y a mejorar la comprensión de la cultura local por parte de los turistas. Esa visión responsable debe articularse sobre algunas nociones de gestión, siendo la gobernanza la herramienta para involucrar a la población local en las decisiones sobre el patrimonio cultural.

El propósito de este trabajo es explorar la activación en los procesos de gobernanza en los ecomuseos, partiendo de la implicación de diferentes agentes en su desarrollo, estableciendo el nivel de participación y la cogestión de la población local en la administración de los recursos del proyecto comunitario. Para ello se ha elegido como caso de estudio el Proyecto Cultural de Desarrollo Comunitario de la Aldea (PDCLA), en la isla de Gran Canaria (Islas Canarias, España). A partir de entrevistas, conversaciones informales, cuestionarios y observación directa, se determina la aplicación de la cogestión del patrimonio como aspecto de gestión responsable.

Para esta investigación, se concibe la cogestión del museo como el conjunto de decisiones y actividades en términos de conservación y desarrollo sustentable del entorno; se asume el principio de la administración comunitaria. De esta manera, constituye un paradigma de gestión con respecto a la dirección tradicional museística (dependiendo de su modelo organizativo).

Se plantea como hipótesis que la cogestión, como forma de aplicación de la gobernanza, se muestra como una herramienta eficaz para el reparto de responsabilidades y competencias en el rendimiento de los recursos, siendo sostenible en el tiempo y contribuyendo a superar crisis intermedias (económicas y sociales).

\section{La cogestión como estrategia de la gobernanza en el ecomuseo}

\subsection{Gobernanza en los museos}

La gobernanza ha ganado protagonismo en los últimos años en diversos sectores de la sociedad, como mecanismo de negociación y cooperación entre diversos actores (a nivel privado o público, y desde el punto de vista individual, empresarial o insti- 
tucional). La Organización de las Naciones Unidas para la Educación, la Ciencia y la Cultura, Unesco (2005, p. 78) propone la gobernanza en el sector del patrimonio para mantener el equilibrio entre los objetivos sociales y económicos, y entre las metas individuales y las comunales. El marco de la gobernanza tiene por finalidad promover el uso eficiente de los recursos y exigir responsabilidades en la administración de esos recursos. Lo que se busca es alinear en la medida de lo posible los intereses de los particulares, el patrimonio cultural y la sociedad.

En el contexto de los museos, se ha tomado la adaptación que hace Legget (2006) para este ámbito: "Los stakeholders de un museo son individuos u organizaciones que tienen un interés o influencia en la capacidad de un museo para lograr sus objetivos". Freeman definió un stakeholder como: "cualquier grupo o individuo identificable que puede afectar o ser afectado por el logro de los objetivos de la empresa" (Freeman, 1984, p.46). El término se utiliza tanto en el ámbito empresarial como en el social: asociaciones, instituciones o colectivos.

Este mecanismo ha sido estudiado en otros contextos, como en las políticas globales de propiedad intelectual, entendiéndola como un conjunto de acuerdos y ordenamientos jurídicos, que en gran medida regulan el flujo de información en internet (Souza et al., 2014), o en políticas medioambientales (Durant, 2017; Newin et al., 2018; Videira et al., 2017). Es en el caso de los museos donde hay especial interés por la vinculación de la diversidad de actores en la formación de estrategias para un desarrollo social, económico y cultural común (Cosmin, 2018; Elsorady, 2018; Loach et al., 2017; Zuned, 2018).

Un desafío fundamental para alcanzar la gobernanza es involucrar a una diversidad de socios y ganar legitimidad (Huxham y Vangen, 2005; Vangen y Huxham, 2012). La atracción misma para colaborar es aprovechar esta diversidad de capacidades y recursos dispares, generar nuevas soluciones y sinergias entre socios en respuesta a este espectro de diversidad de retos. La gobernanza es discutida en la literatura desde diversas dimensiones. Primero, por el grado de colaboración a corto plazo o a largo plazo (Keast et al., 2007). En segundo lugar, el nivel de formalidad y rango de centralización, desde una red suelta a una fuerte asociación con su propia entidad legal, administración, organización y personal (Bryson et al., 2006; Provan y Kenis, 2008). Tercero, hay sistemas de rendición de cuentas que aclaran quién de la asociación es responsable y para qué (Geddes y Shand, 2013). Finalmente, existe el valor de apertura en el grado de participación de los miembros y claridad de roles asignados (Huxham y Vangen, 2000), a través de personas que representan socios sin asignación preesta- 
blecida de roles. Son esos miembros, o voluntarios, los encargados de intervenir en la cogestión de los recursos del espacio cultural, en este estudio los museos.

El término "cogestión", también referida como gestión participativa, coadministración, o gestión compartida, constituye un "arreglo institucional entre los usuarios locales de un territorio o conjunto de recursos naturales y/o grupos interesados en su conservación, y las agencias públicas a cargo de la administración de estos recursos. Implica tanto un reparto de responsabilidades y competencias, como una clara definición entre el ejercicio de la autoridad pública y las pautas de uso, acceso, control y posterior manejo de los recursos" (Girot, 1998). El mismo autor menciona que la cogestión es en esencia un partnership (asociación) entre partes que comparten un interés, una responsabilidad y una visión sobre el uso sostenible de un recurso. Esas alianzas deben incluir a diversos sectores. En el campo de los museos, la cogestión pasa por el uso participativo de las comunidades de las áreas afines a espacios ecoculturales o en vías de musealización (Adán, 2010; Janes, 2016). Esa ecogestión tiene como reto alcanzar acuerdos entre los diversos sectores económicos que conforman el tejido productivo en un área determinada.

\subsection{Desafíos de las alianzas intersectoriales}

Una asociación intersectorial (un museo) involucra al público, sectores privados y terceros que trabajan juntos para gestionar recursos y capacidades, compartir las decisiones a tomar a medio y largo plazo, o para abordar un problema social complejo (Selsky y Parker, 2005; Bryson et al., 2006). La literatura existente en cuanto a alianzas intersectoriales es muy diversa y depende específicamente del sector determinado (Huxham y Vangen, 2005; Bryson et al., 2006).

Hay un alto costo directo para cada socio que conforme la red de alianzas: tiempo del personal, contribución financiera, compartir activos e información. En un sector transversal, como la cultura, las asociaciones se toman tiempo para llegar a buen término y la entrega es a menudo lenta. Con frecuencia muchas asociaciones intersectoriales no logran sus objetivos. La literatura sobre el sector transversal respecto a asociaciones se puede resumir en relación con tres desafíos particulares: gobernanza, estrategia y liderazgo.

Estudios previos caracterizan la naturaleza de la estrategia como multinivel, interconexión, dinámica, y como resultado, con consecuencias no deseadas (Seitanidi, 2008; Clarke y Fuller, 2010; Vangen y Huxham, 2012). Es por lo que muchos autores enfatizan la necesidad de negociar un acuerdo sobre un propósito, pero hay una 
división en la literatura sobre la mejor manera de superar este problema (una forma rápida y otra más lenta).

El desafío inicial de liderazgo es crear asociación (Crosby, 2010; Klijn et al., 2010), que es ayudado por una organización o coordinador poderoso, creíble, comprometido a largo plazo, capaz de replantear y elevar el perfil del problema, y tiene un gran capital (Waddock y Post, 1991; Bryson et al., 2006). Una vez que la asociación intersectorial se ha iniciado, los líderes necesitan equilibrar el número y diversidad de personas involucradas, entre una más democrática (Bryson et al., 2006), o un enfoque selectivo (Klijn et al., 2010). Cuando surjan conflictos, los líderes deben tener un rol esencial de mediación (Crosby y Bryson, 2010; Klijn et al., 2010).

En la revisión literaria, por un lado, destaca la necesidad de contar con un líder individual fuerte, ya sea desde el sector público (o privado) basado en la autoridad (Ansell and Gash, 2008; Crosby, 2010; Geddes y Shand, 2013), o un emprendedor social privado (Waddock y Post, 1991).

\section{El Proyecto Cultural de Desarrollo Comunitario de La Aldea}

\subsection{Proyecto de Desarrollo Comunitario de La Aldea}

EI PDCLA surge en un contexto muy específico en el que gran parte de las razones que llevaron a su creación vienen determinadas por las especiales condiciones geográficas en que se encuentra. La Aldea de San Nicolás se ubica al oeste de la isla de Gran Canaria (Mapa 1) y está rodeada por una agreste orografía. Este hecho explica su aislamiento durante muchos siglos: la primera carretera que llegó a La Aldea de San Nicolás se construyó en 1939, desde Agaete. Anteriormente, las comunicaciones con el exterior se realizaban por mar. Su relieve, erosionado y muy abrupto, está seccionado por numerosos barrancos. Su clima es seco con un paisaje semiárido lo que ha determinado la proliferación de pequeños núcleos diseminados a lo largo del municipio buscando las zonas más húmedas, planos de barrancos y sus alturas coronadas de extensos pinares (López, 2003; Sánchez, Suárez y Moya, 2002). El municipio de La Aldea San Nicolás se encuentra a unos 50 kilómetros de la capital de la isla, Las Palmas de Gran Canaria, y 63 o 111 kilómetros según la ruta escogida, del área turística de la isla (Maspalomas - Puerto Rico). La población es de 7 mil 504 habitantes (2019). El cultivo del tomate es la principal actividad del municipio (Cabildo de Gran Canaria, 2018). 
Figura 1. Mapa de localización del Proyecto Comunitario de La Aldea.

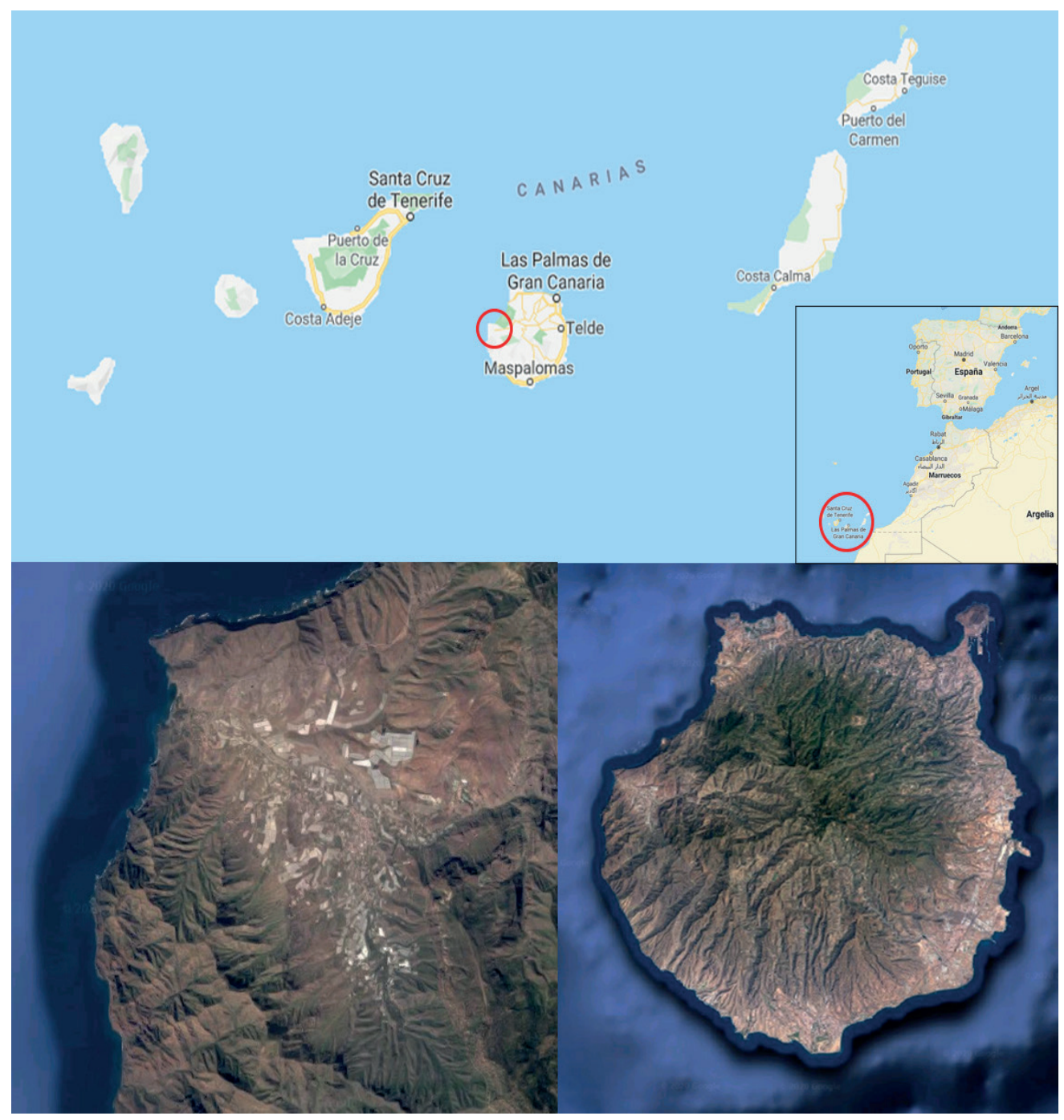

Fuente: Elaboración propia.

Este aislamiento y la proliferación de barrios y pequeños núcleos poblacionales diseminados pueden ayudarnos a entender la conservación, riqueza y variedad del legado etnográfico que el municipio posee.

El PDCLA comienza cuando dos maestros del Colegio Público Cuermeja (aún en activo), José Pedro Suárez y Lidia Sánchez, deciden incorporar la cultura popular a las actividades del centro educativo en el que trabajaban. Esto ocurrió en 1980, en la Residencia Escolar de La Aldea de San Nicolás. La preocupación del profesorado por 
lograr la convivencia llevaba aparejada la idea de reducir los efectos negativos que la prolongada separación de sus entornos familiares podría tener sobre los residentes. De esta manera surge una experiencia didáctica y etnográfica encomiable (Sánchez, Suárez y Moya, 2002).

Figura 2. Visitantes entrando al Centro Locero

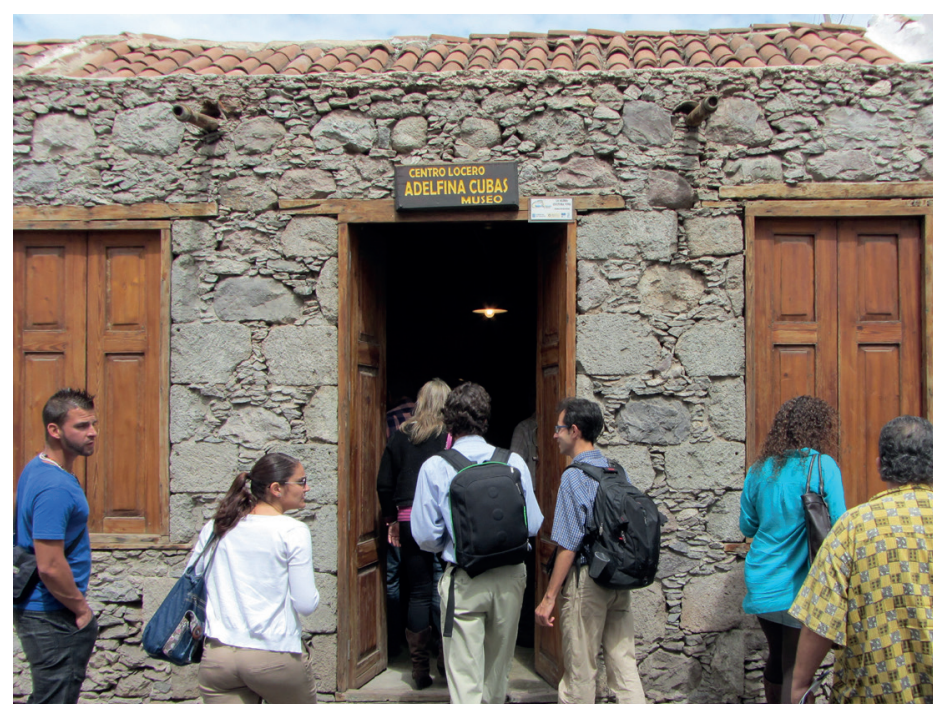

Foto: Agustín Santana Talavera (septiembre de 2017).

Figura 3. Visitantes en el Molino de Gofio

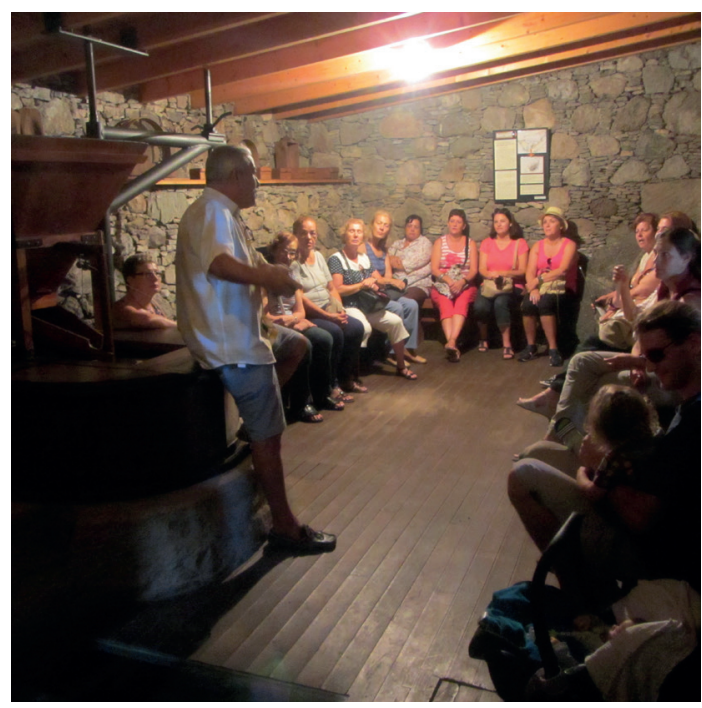

Foto: Héctor Moreno Mendoza (febrero de 2020). 
Esta experiencia de participación etnográfica divulgativa ha sido reconocida nacional e internacionalmente por sus valores culturales y educativos, pero fundamentalmente por su preocupación por la recuperación y trasmisión del patrimonio inmaterial. La Unesco (2011) considera patrimonio inmaterial las tradiciones que se transmiten oralmente o mediante gestos y se modifican con el transcurso del tiempo a través de un proceso de recreación colectiva, siendo cada individuo el portador del patrimonio de su propia comunidad. Se incluyen las tradiciones orales, las costumbres, las lenguas, la música, los bailes, los rituales, las fiestas, la medicina tradicional y la farmacopea, las artes culinarias y todas las habilidades especiales relacionadas con los aspectos materiales de la cultura, tales como las herramientas y el hábitat.

En definitiva, en el caso del PDCLA, según sus gestores, es aquel que nos aporta frescura, sentimientos y vivencias a través de nuestros recuerdos: olores, sonidos, expresiones, imágenes, etc., que están en la memoria de nuestros mayores, como testigos excepcionales de todas aquellas vivencias que hoy perviven en el recuerdo como referente cultural y que ha sido considerado por el Comité Científico Internacional de Museos, como "el museo vivo más importante de Europa" (Sánchez y Suárez, 2006).

\subsection{Descripción}

Son diversas actividades las que conforman el PDCLA: los Museos vivos (ver figura 4 con la distribución de los museos en el núcleo del municipio), los talleres de artesanía, los deportes autóctonos, las Jornadas Anuales Regionales de Folclore, la participación en actos populares (Auto de los Reyes Magos, Rancho de Ánimas), entre otros. Desde su creación, el proyecto de desarrollo comunitario ha ido generando numerosos museos vivos (Anderson, 1982; Naumova, 2015), donde se puede disfrutar con las tradiciones: ordeñar, arar, trillar, amasar, hacer el queso, conocer en vivo todas las tradiciones artesanales recuperadas, visitar una escuela tradicional, un almacén de tomates acompañado por el capataz, la tienda de aceite y vinagre por un tendero, entre otros. (Sánchez, Suárez y Moya, 2002). 
Figura 4. Croquis de la distribución de museos en el PDCLA

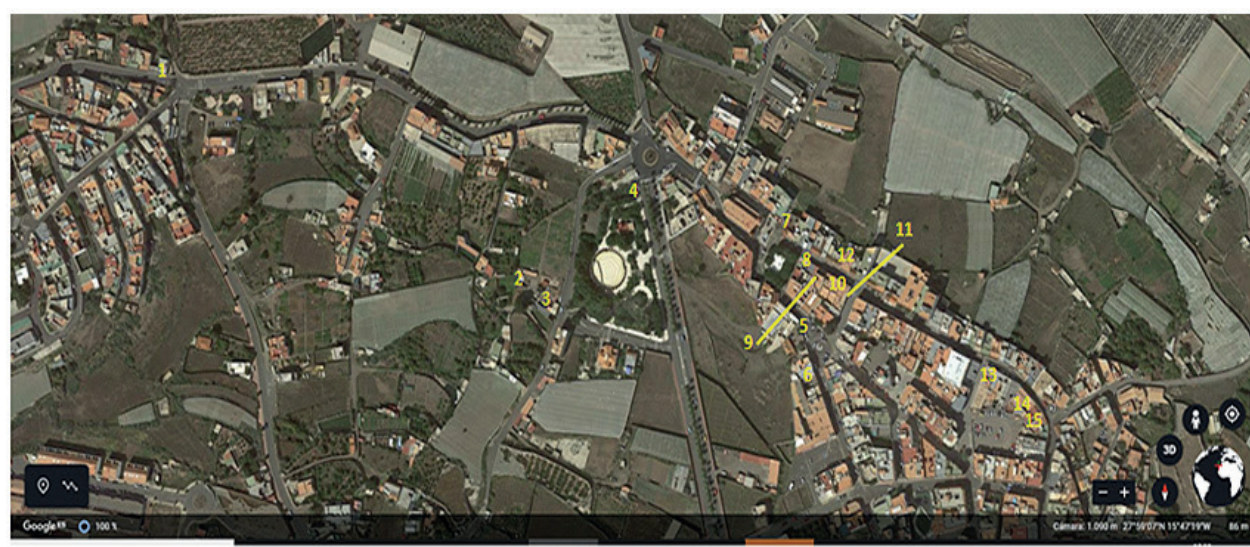

$\begin{array}{lll}\text { Leyenda: Museos La Aldea } & & \\ \text { 1 Molino de Gofio } & 6 \text { Almacén de Tomates } & \text { 11 Carpintería } \\ \text { 2 Gañanía } & \text { 7 Escuela } & \text { 12 Centro Locero } \\ \text { 3 Museo del Pastor } & \text { 8 Barbería } & 13 \text { Museo de la Música } \\ 4 \text { Herrería } & 9 \text { Museo Vestimenta Tradicional } & \text { 14 Tienda } \\ 5 \text { Museo Medicina Rural } & \text { 10Zapatería } & \text { 15 Carnicería }\end{array}$

Fuente: Elaboración propia a partir de google earth.

El Proyecto comenzó con La Gañanía, una finca tradicional de principios del siglo XX con estancias originales donde se muestran las formas de vida de la cultura rural, y el molino de agua para moler el gofio ${ }^{1}$ una edificación de finales de siglo XIX que ha sido reconstruida (Sánchez, Suárez y Moya, 2002). A continuación, se incorporaron otros museos con los oficios y actividades del pueblo en el siglo XX: la tienda, museo de la música, centro locero, la barbería, la escuela, el almacén de tomates, la zapatería, la medicina rural, la carpintería, la herrería y la carnicería (Suárez y otros, 2005). Los dos últimos espacios incorporados al Proyecto son el museo del pastor (2014) y el museo de la vestimenta tradicional (2016).

\subsection{Oferta permanente y temporal}

Se pueden realizar tres visitas o rutas distintas: una primera, "corta", visitando el molino de gofio, el museo del pastor y la Gañanía, donde se pueden realizar diferentes tareas: amasar, hacer pan; hacer gofio, descamisar (quitar la vaina o cáscara a las piñas o mazorcas), desgranar, aventar, tostar o moler. Una segunda, "media", donde se muestran oficios y formas de vida de antaño, visitando la herrería, la escuela, el almacén de tomates, la tienda, la zapatería, la barbería, la medicina rural, el centro

\footnotetext{
Producto alimenticio heredado de las culturas aborígenes canarias que sigue vigente; actualmente se pueden hacer variedades con varios cereales, el más usual es el millo molido que se mezcla con azúcar. Equivale al "pinole" mexicano.
} 
locero, el museo de la música, la carpintería, la carnicería y el museo de la vestimenta tradicional. se pueden ver todos o algunos museos que más tengan interés para el grupo visitante. Y una tercera, "larga”: el molino de gofio, la Gañanía, el museo del pastor, la herrería, la escuela, la medicina rural, la barbería, la carpintería, la zapatería, el centro locero, el museo de la música, la tienda, la carnicería, el almacén de tomates y el museo de la vestimenta tradicional. Esta ruta también es configurable en cuanto a espacios.

\subsection{Aspectos de gestión}

Como aspectos de gestión, los horarios se pueden concertar con la organización, se suele adaptar a las necesidades del grupo (se pide que sean un mínimo de 10 personas, no hay máximo, aunque no se recomiendan grupos mayores a 25 personas). La entrada es gratuita. El museo dispone de folletos (solo en español y en digital), paneles y carteles (español), visitas guiadas (español) y no cuenta con videos o proyecciones.

El Proyecto se conforma como una asociación sin ánimo de lucro, dirigido por una asamblea que es coordinada por un presidente, un vicepresidente, un tesorero, un secretario y un vocal. La asamblea es la forma de gobierno en el Proyecto. Se reúnen dos veces, martes y jueves, todas las semanas. Normalmente se reúnen 50 personas. Los cargos directivos son asignados mediante propuestas. Se realizan votaciones para tomar decisiones. Hay un estatuto y una memoria de asociación. Las decisiones se toman en la asamblea, mediante consenso o voto directo o delegado para llegar a acuerdos.

Los ingresos anuales, $15000 €$ (2019), proceden de una subvención de la Fundación para la Etnografía y Desarrollo de la Artesanía Canaria (FEDAC, Fundación Autónoma perteneciente al Cabildo de Gran Canaria). Durante mucho tiempo no estuvieron adscritos ni registrados. Ahora conforman una asociación. En cuanto al personal, el número de implicados directo es de 45 voluntarios. Para algunos actos se superan los 200 participantes.

El Proyecto no dispone de cafetería o restaurante, ni de tienda de souvenirs; no hay personal contratado para limpieza, seguridad o visitas guiadas. Como política del Proyecto nunca critican la relación mantenida con los gobiernos. Se tiene un convenio de colaboración con la Consejería de Educación del Gobierno de Canarias. Existe otro convenio con la FEDAC, para poder pagar alquileres y comida para los animales. Con el ayuntamiento local no existe ningún convenio. No hay relación (para toma de decisiones o financiación) con empresas privadas. Por ejemplo, si hay que acudir a un congreso, el proyecto o en ocasiones sus miembros tienen que pagar todos los gastos. 


\subsection{Gobernanza (principios y criterios) y actores en el ecomuseo}

Después de la observación directa realizada y de las entrevistas que se han llevado a cabo, se determina que el Proyecto cumple con los 35 criterios de los cinco principios de gobernanza: Legitimidad y voz, Dirección (visión estratégica), Eficacia y eficiencia (rendimiento), Responsabilidad y transparencia (rendición de cuentas) y Justicia (cumplimiento de la ley). Algunos aspectos destacados con relación a la gobernanza son: Los voluntarios participan de forma activa en la toma de decisiones. Además, los representantes delegan las decisiones en los implicados. En el Proyecto se fomenta el debate, se comparten las decisiones a tomar, y existe una memoria anual donde se establecen los objetivos del año siguiente. Los responsables creen que existe diversidad y eficacia, así como una gran labor de aprendizaje por lo hecho y por lo que se está por hacer. Los representantes afirman que nunca ha habido desconfianza con este modelo de gestión. Los únicos problemas podrían estar relacionados con tendencias políticas (aunque el Proyecto no se implique políticamente), y el referente al presupuesto anual. No ha habido nunca problemas legales que afecten a los implicados.

El grupo humano (los voluntarios) es el stakeholder (implicado) principal de este proyecto. Cada voluntario cuenta con una función específica en el grupo. Los responsables de esta asociación se consideran a sí mismos mediadores en las relaciones diversas entre los asociados y voluntarios, fundamentalmente a partir del conocimiento personal sobre los detalles significativos en cada caso. Su estrategia consiste en dar protagonismo a quien socialmente se considera relevante en un ámbito determinado (el carpintero en la carpintería o el maestro en la escuela), evitando suplantar protagonismos pese a las cambiantes relaciones de amistad. 40 años de experiencia en el proyecto avalan el conocimiento y reconocimiento que unos tienen de los otros, por lo que los liderazgos son compartidos según las destrezas individuales percibidas por los implicados (prestigio y respeto profesional).

Las personas que conforman el proyecto son las que poseen los atributos de poder, legitimidad y urgencia, todas sin excepciones, ya que sin ellos no se podría continuar con el proyecto. Cada una de esas personas representa una parte importante de un propósito colectivo que es la suma de conocimientos y aportaciones individuales, tanto materiales como inmateriales. 
Figura 5. Haciendo el queso en la Gañanía

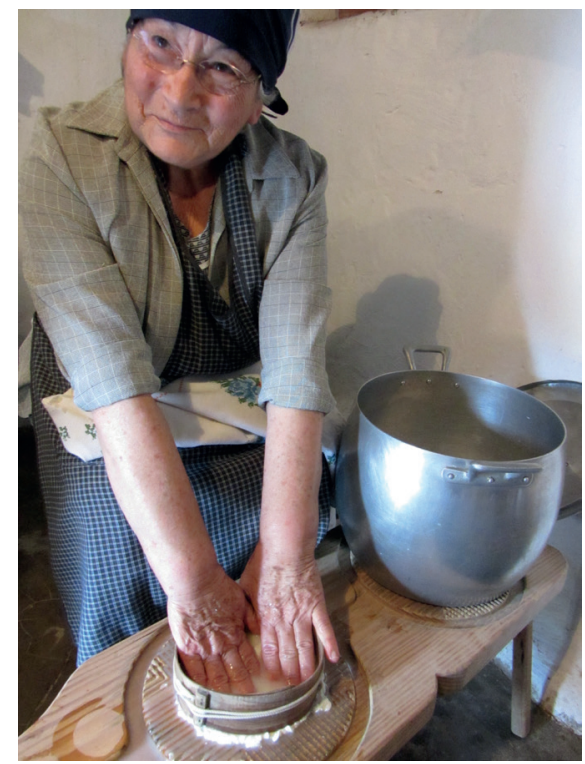

Foto: Héctor Moreno Mendoza (septiembre de 2017)..

\section{Metodología}

El propósito de este trabajo es explorar la activación en los procesos de gobernanza en el PDCLA, partiendo de la implicación de diferentes agentes en su desarrollo, estableciendo el nivel de participación y la cogestión de la población local en la administración de los recursos. Se ha optado por una estrategia de investigación cualitativa centrada sobre el caso de estudio (Eisenhardt, 2002; Hamel et al., 1993; Simons, 2011; Yacuzzi, 2005; Yin 2003). La selección del caso se realizó tras una revisión de los museos insulares (Gran Canaria, España), atendiendo al mejor referente de ecomuseo existente en la isla de Gran Canaria, el cual recibe más de cuatro mil visitas anuales (Tabla 1). Las aplicaciones posteriores, al menos parcialmente, siguen el trabajo de Adie y Hall (2017), que realizan un análisis comparativo de tres casos de estudio de sitios culturales a través de encuestas realizadas a visitantes.

Para este estudio, se toma un enfoque cualitativo (Shaw e Ivens, 2002). La aplicación de esta perspectiva se aplica mediante el análisis de las respuestas de los cuestionarios, determinando la muestra según el grado de saturación detectado en respuestas abiertas (Thomas y James, 2006), y contrastando esa información con la obtenida a través de otras técnicas como la entrevista en profundidad, la entrevista conversacional y la observación directa. 
Tabla 1. Distribución de los visitantes en el caso de estudio.

\begin{tabular}{|c|c|c|c|c|c|c|}
\hline Visitas (2019) & Total & $\begin{array}{c}\text { Escolares y colec- } \\
\text { tivos \% }\end{array}$ & Insulares \% & Nacionales \% & Internacionales\% & Actividades \% \\
\hline P.C. Aldea & 4600 & 56 & 15 & 10 & 15 & 4 \\
\hline
\end{tabular}

Fuente: Elaboración propia.

Partiendo de los problemas destacados en el marco teórico de la investigación, y los objetivos que la focalizan, se elaboró un cuestionario guía para las entrevistas (en profundidad y conversacionales), decidiendo que se permitiría a los informantes introducir temas de interés. Esta estrategia permite que, más allá de la información relevante, los informantes aporten matices que ayudan en la interpretación.

Para las entrevistas se consideró tomar a los responsables de la gestión como informantes clave, estableciendo una guía semiestructurada que planteaba 14 temas o cuestiones de interés (beneficios, aportación personal, vínculos emocionales, visión, aportación a la persona, elementos destacables, elementos que cambiaría, forma de gestión, conflictos, visitantes y visibilidad, profesionalización, problemas y retos, futuro del mismo). Las entrevistas tuvieron una duración aproximada preestablecida de 45 minutos. Se llevó a cabo la grabación digital de audio de cada una, favoreciendo la interpretación (Yin, 2003).

Las entrevistas realizadas, complementadas con observación directa, sirvieron para determinar los objetivos e hipótesis planteadas. Estas técnicas contribuyen a la determinación cualitativa de la gestión del museo, orientando la interpretación de resultados en el análisis realizado con el CAODAS (Software informático para análisis de información cualitativa).

Se llevaron a cabo diez conversaciones informales con responsables de diversos negocios en el entorno del Proyecto: cafeterías, panadería, farmacia, supermercado, tienda de ropa, entre otros. Las dos cuestiones principales tratadas versaron sobre los beneficios aportados por el Proyecto a la economía local y la conveniencia de la sostenibilidad del Proyecto en el tiempo.

En una fase previa a las entrevistas, se realizó un cuestionario a una muestra aleatoria simple, determinada por saturación, de 100 visitantes (tabla 2). Los investigadores toman datos hasta que se produce una saturación de información. 
Tabla 2. Periodo, áreas y características sociodemográficas de la encuesta

\begin{tabular}{|c|c|c|c|}
\hline Periodo & \multicolumn{3}{|l|}{ 29/7/2017 - 21/12/2017 } \\
\hline Muestreo & \multicolumn{3}{|c|}{ Proyecto Comunitario La Aldea (100 cuestionarios) } \\
\hline Muestra & 100 (Muestreo intencional) & Sistema de recogida de datos & PAPI \\
\hline Edad & $\begin{array}{c}<18 \text { años: } 7.4 \% \\
18 \text { - } 30 \text { años: } 15.6 \% \\
31 \text { - } 50 \text { años: } 37.4 \% \\
51 \text { - } 70 \text { años: } 31.8 \% \\
>70 \text { años: } 6,2 \% \\
\text { NC: } 1.6 \%\end{array}$ & Género & $\begin{array}{c}\text { Mujer } 54.6 \% \\
\text { Hombre } 44.2 \% \\
\text { No Contesta: } 1.2 \%\end{array}$ \\
\hline
\end{tabular}

Fuente: Elaboración propia.

El cuestionario se diseñó para valorar la opinión de los visitantes, distribuido en 14 preguntas: 1) país de residencia, 2) tipo de alojamiento, 3) cómo ha llegado al museo, 4) con quién visita el museo, 5) edad, 6) género, 7) razones de la visita, 8) cómo conoció el museo, 9) ha realizado visita guiada (calidad y tiempo), 10) valorar características (trato, ambiente, presentación, calidad y utilidad, aprendizaje, interés, accesibilidad, señalización, precio de las entradas, servicios, y tiempo de espera, 11) calidad - precio, 12) aspectos que "le gustó", 13) aspectos que "no le gustó" y 14) sugerencias.

Para analizar el contenido y proceder a la codificación de las tres últimas, debido a la posibilidad tan amplia en las respuestas, ya que las preguntas eran abiertas, se establecieron ocho categorías en cuanto al contenido de los mismos, tomando como referencia los aspectos del museo que establece el Laboratorio Permanente de Público de Museos del (Ministerio de Educación, Cultura y Deporte, 2013): 1) exposición, 2) comunicación e información, 3) funcionamiento, 4) conservación, 5) instalaciones, 6) personal, 7) promoción y 8) otros.

Para realizar el análisis cualitativo y que este sea efectivo (Gibbs, 2012), la gestión de datos ha sido eficiente, coherente y sistemática. Para ello se ha utilizó un CAQDAS, concretamente Nvivo 10.

Se inició la tarea en Nvivo con la importación de la información, a través de elementos internos (cuestionarios, entrevistas y notas observacionales) y elementos externos (tomados de las redes sociales y páginas webs del museo), estos últimos con la herramienta Ncapture. A continuación, se realizó la codificación (reunir material por temas, tópico o caso) y creación de nodos (apartados que permiten recopilar información y buscar por patrones). Se ha codificado la información mediante la "codificación 
automática basada en patrones", luego se vinculan activamente todos los nodos y documentos. A partir de esta tarea, se realizaron consultas para buscar y analizar palabras o frases en los recursos o nodos, enfatizando la frecuencia de aparición en los discursos tratados. Con esto fue posible iniciar la búsqueda de patrones basados en la clasificación, comprobando su congruencia y triangulando con lo observado en el trabajo de campo.

Para finalizar, se exploraron los datos a partir de gráficas, modelos u otras técnicas de visualización. Esto sirvió para ayudar a explorar tendencias y probar teorías. A medida que el proyecto ha ido avanzando, se han realizado informes, cuyo interés ha sido a) analizar y revisar el avance, b) identificar temas que ocurren con más frecuencia, y c) presentar conclusiones.

\section{Resultados}

La necesidad de correlacionar la intención del proceso de participación, y por extensión los principios de la gobernanza, con las características específicas de los museos, se muestra como un aspecto relevante debido a las implicaciones socioeconómicas e identitarias que tienen estas implicaciones culturales sobre las poblaciones vinculadas. Ha sido determinante la identificación de actores principales (voluntarios) y secundarios (vinculados al proyecto), tanto reales como potenciales que tengan la capacidad de influir en la red y, con ello, poder tomar parte en los acuerdos alcanzados sobre la oferta cultural. Pero también la concreción de los recursos financieros que, más allá de la profesionalización, condiciona el equipamiento, contenido del museo, oferta temporal o servicios. Ambos factores concurrentes, actores implicados y financiación, marcarán las posibles estrategias para el uso más eficiente de los recursos existentes y el cumplimiento de los objetivos fijados por las propias instituciones patrimoniales.

El enfoque tradicional en la gestión de los museos es, generalmente y con excepciones, incapaz de evaluar los efectos que tendría la incorporación de nuevos agentes y nuevas formas de gestión en la estrategia concerniente a agentes involucrados o con la capacidad de serlo. Con las herramientas utilizadas (observación directa, entrevistas al staff de los museos y cuestionarios al público, que triangulan la información (Patton, 2002), se interpretarán los resultados obtenidos con Nvivo, del caso de estudio tratado. 


\subsection{Modelo de gestión y sus limitaciones}

Cabe destacar que en el caso del Proyecto Comunitario La Aldea, la proyección de imagen y la consecuente captación de público es tremendamente intuitiva y no profesional, conformando un modelo de gestión frágil. En este caso, basado en el voluntariado local y de régimen asambleario, se reúne dos veces por semana (generalmente unas 40 personas, con delegación de voto entre sus miembros), tomándose las decisiones de funcionamiento e incluso de nuevos proyectos (cada proyecto con un/a coordinador/a) de manera participada en régimen de mayorías. Conseguido el liderazgo, propuesto individualmente, pero aceptado por una mayoría, se enfrenta al reto estructural de obtener financiación.

Se podría observar que, en la ejecución final, sus compromisos de conservación, difusión y mejora de los usos del Patrimonio, estará en gran medida enmarcada en la distribución de recursos económicos. Sin embargo, la estructura que delimita tanto los acuerdos internos como las relaciones con su entorno, en sentido amplio, contribuyen en gran parte al grado de agilidad en la ejecución de proyectos. El Proyecto Comunitario La Aldea, es capaz de ejecutar pequeñas (en duración y público objetivo) muestras y actividades museísticas casi autogestionadas y autofinanciadas por sus promotores.

Tabla 3. Características del modelo de gestión del Proyecto Comunitario de La Aldea.

\begin{tabular}{|l|l|}
\hline \multicolumn{1}{|c|}{ Características } & \multicolumn{1}{c|}{ Proyecto Comunitario de La Aldea } \\
\hline Titularidad & Privada \\
\hline Financiación & Dependiente de subvenciones, convenios y donaciones \\
\hline Consejo de administración & Autogobierno. Solo sometido al aval dado por la asamblea \\
\hline Personal & Voluntarios. Cada uno se implica en lo que sabe y puede sin remuneración \\
\hline Núm. de personal & 45 voluntarios fijos \\
\hline Financiación (2019) & Aprox. 200 voluntarios eventuales \\
\hline Fuente de financiación & $15000 €$ \\
\hline Modelo de toma de decisiones & Subvención de la Fundación para la Etnografía y Desarrollo de la Artesanía Canaria \\
\hline Donaciones & (FEDAC. Cabildo de Gran Canaria) \\
\hline Relación público-privada & Asambleario. Cargos directivos elegidos. \\
\hline Cumplimiento 35 criterios de gobernanza & Cumple \\
\hline
\end{tabular}

Fuente: Elaboración propia. 
La representación de la estructura organizativa y la financiación hace perceptible un gradiente que va de la profesionalización de la actividad al voluntarismo emotivo. Es de destacar el compromiso de cada miembro de una comunidad con un proyecto. Se da por bueno a través de su propuesta y demostración, aportando cada cual su tiempo y experiencia concreta.

El análisis del ecomuseo muestra una carencia de relaciones con el tejido empresarial insular. Esa falta de relaciones, en gran parte es debido a la carencia de visión estratégica y responsabilidades comerciales del Proyecto, pero también por el carácter voluntario de sus integrantes. Canarias centra su economía en la prestación de servicios, recibiendo de 13.1 millones de turistas en 2019, de los cuales la isla de Gran Canaria tiene más de 4 millones. Estos visitantes se alojan en 164 hoteles y 425 establecimientos no hoteleros, pero además habría que contar una multiplicidad de empresas de transporte (autobuses y vehículos de alquiler), gastronomía y restauración, servicios de ocio (especialmente agencias de viaje y guías turísticos), entre otros. La no implicación directa de las empresas en la actividad de representación patrimonial, cuando la cultura se contempla como un complemento al viaje (solo el 2.6\% lo declara un motivo para elegir la elección de Canarias), es muestra del escaso interés mostrado por los promotores del patrimonio y el convencimiento, más allá de sus límites estrictos, de que lo Público debe garantizar el estudio, la conservación y la difusión, incluyendo la función educativa e identitaria.

Cierto es que el desempeño de un museo/sitio patrimonial se debe, por principio y legislativamente, en primer lugar, a las poblaciones locales - aunque la definición de lo local en un mundo globalizado es bastante incierta (Borja y Castells, 2006; Catrina, 2015). La gobernanza, como mecanismo de participación democrática (Mercer, 2005), es un compromiso no paritario con las complejas áreas de las relaciones de poder económicas, humanas y socioculturales, donde la ciudadanía es copartícipe, implicados y actores. En principio cualquier museo, a la hora de tomar decisiones museográficas y de extensión social, debe tener en cuenta que el visitante juega un papel importante. Ello sin olvidar su responsabilidad económica con el territorio y, por tanto, su compromiso de visibilidad, en este caso, ante los residentes y los turistas. 
Figura 6. Museo de la música

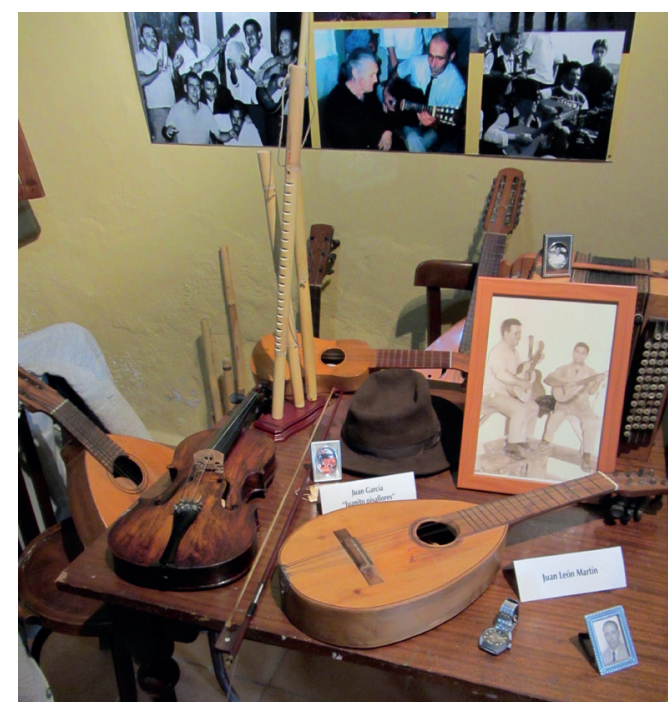

Foto: Agustín Santana Talavera (diciembre de 2019).

En este análisis es notoria la dificultad del Proyecto de pertenecer a circuitos turísti$\cos$ ( $9 \%$ turistas), pero es necesario aclarar el contexto territorial. Además, el Proyecto Comunitario es prácticamente invisible tanto en la promoción turística como para la población insular. Al olvido y dificultad de comunicaciones estructurales e históricas de este municipio, se suma también lo patrimonial.

Figura 7. Museo de la Escuela

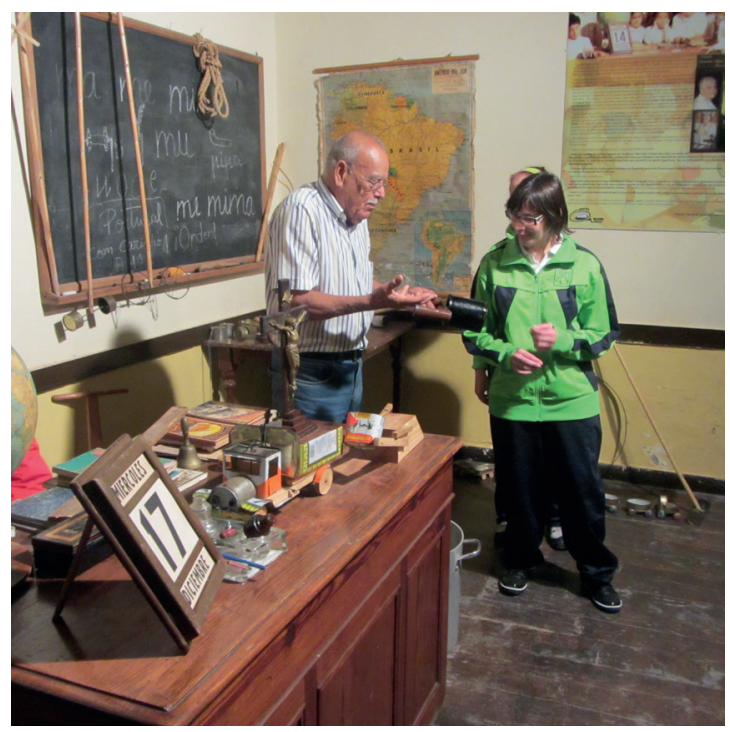

Foto: Agustín Santana Talavera (diciembre de 2017). 
Tabla 4. Caracterización y opinión de los visitantes del Proyecto Comunitario de La Aldea.

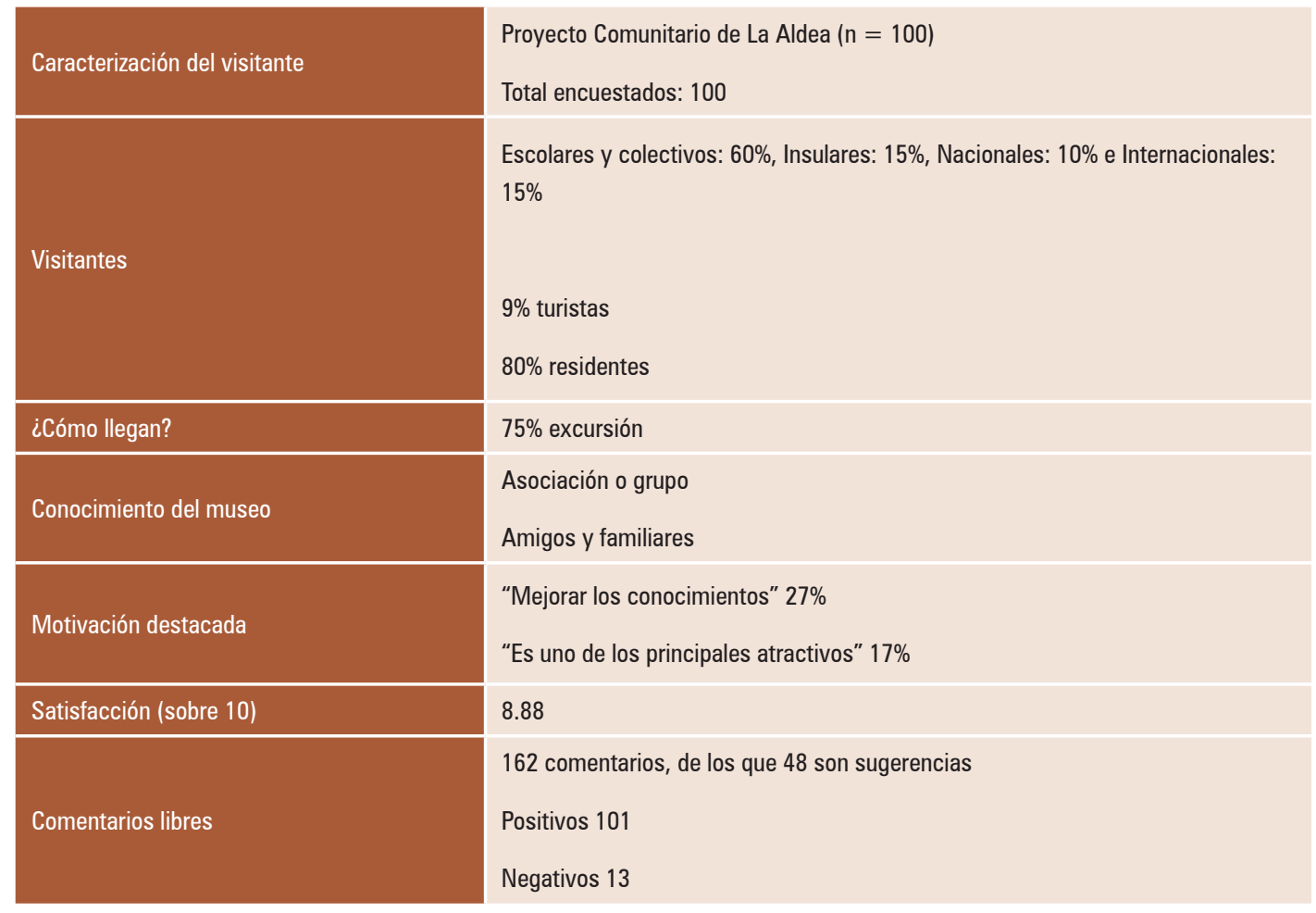

Fuente: Elaboración propia.

Tratando de medir la satisfacción de la visita, se solicitó a los encuestados calificar en escala Likert 10 una serie de aspectos (trato, ambiente, presentación, claridad y utilidad de contenidos, aprendizaje, interés, accesibilidad, señalización, entradas, servicios, esperas), obteniendo una media de 8.88. Los aspectos mejor valorados fueron el aprendizaje (9.5) y el trato (9.4), mientas que los peor valorados fueron la accesibilidad (8.7) y los servicios (6.5). Estos datos pueden, tomados de manera sistemática, contribuir a mejorar las encomiendas del Proyecto, dando voz a los visitantes. Sin embargo, más destacable es el número y la calidad de los comentarios o respuestas libres que muestran el interés de los visitantes por intervenir en el proceso de representación patrimonial.

Más allá de solicitar mejoras en los servicios, del tipo incluir restauración o tienda de souvenirs (que no dejan de ser importantes en estos contextos patrimoniales y de ocio), los visitantes indican que desean otras cuestiones, como, por ejemplo: que debe adaptarse la comunicación de contenidos (videos y folletos). El problema radica en la falta de profesionalización y medios para contar con un equipo responsable de la comunicación. De hecho, el folleto disponible para públicos, no escolar, no reúne las características apropiadas para la comunicación de contenido patrimonial. 
Figura 8. Un grupo de alumnos aprendiendo a sembrar en la Gañanía

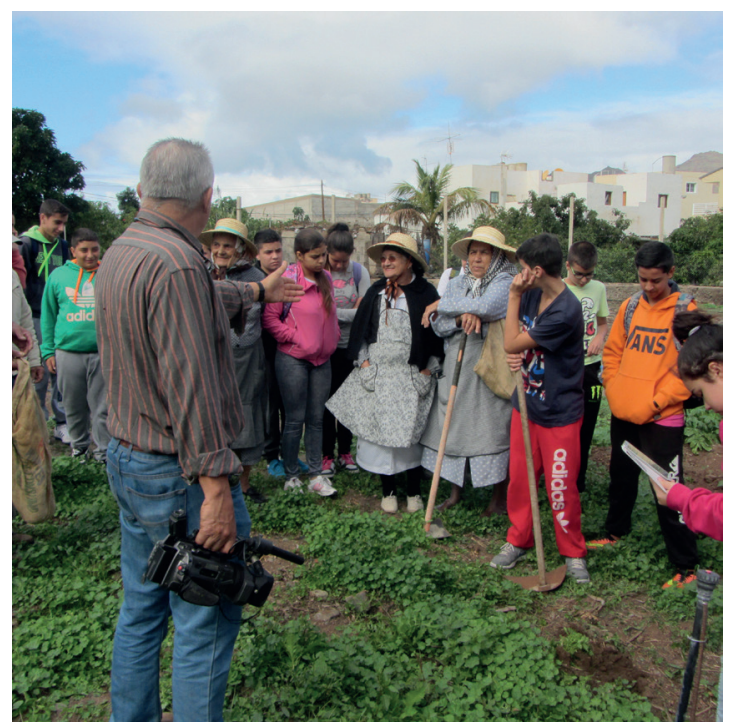

Foto: Héctor Moreno Mendoza (noviembre de 2017).

\subsection{La gobernanza en el Proyecto de desarrollo comunitario}

La gobernanza como mecanismo de ejercer el poder, puede ser establecida a través de 5 principios y 35 criterios (Agarwal et al., 2016; Graham et al., 2003). En el caso del Proyecto Comunitario de la Aldea se ha determinado que se cumplen con la totalidad de principios y criterios.

Como se indicó líneas arriba, el voluntariado, conformado en asamblea, es el stakeholder principal de la acción patrimonial. Se trata de un grupo de personas que, desde 1980, han tratado de transmitir valores etnográficos que se consideran parte de la tradición, configurando un conjunto vivo de representaciones museísticas. A partir de un núcleo más o menos estable, se reúnen de manera flexible entre 200 y 300 personas, a quienes se les otorga roles y funciones específicas. En un tiempo prolongado y con diversidad de pareceres, la responsabilidad de gestionar las relaciones personales ha recaído en los líderes electos. Pequeños detalles pueden ser interpretados como agravios, se suscitan rivalidades o celos, con lo que la gobernanza y liderazgo interno se vuelve tan importante como el externo. Los responsables son los encargados tanto de dar protagonismo al que lo merece dentro de su ámbito, dejando espacios internos para la toma de decisiones y tratando de cubrir la diversidad existente, como de mediar en los posibles conflictos. 
Figura 9. Voluntaria explicando la molida del Gofio

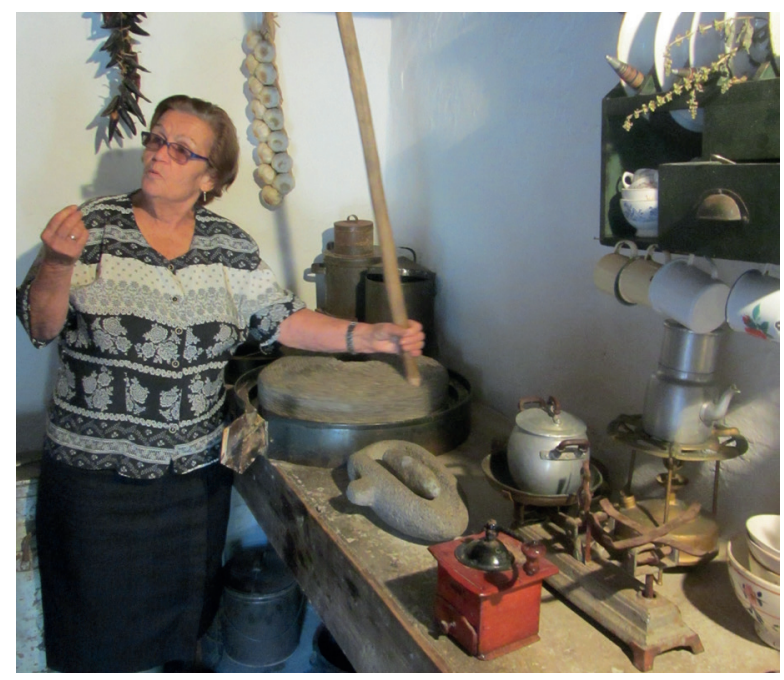

Foto: Agustín Santana Talavera (diciembre de 2018).

\subsection{Entrevistas a voluntarios}

Las entrevistas se realizaron a 10 voluntarios de los más activos del Proyecto, con edades comprendidas entre los 66 y 86 años: cuatro mujeres y seis hombres. Con las entrevistas realizadas, se corrobora que el Proyecto ha sido favorable para la comunidad, ya que ha aportado beneficios económicos y sociales. A nivel personal, a los voluntarios les ha aportado alegría, voluntad y entretenimiento. Se deduce que las principales aportaciones han sido la recuperación de tradiciones perdidas o a punto de perderse y las vivencias de aprendizaje de los propios voluntarios. Algunas de esas tradiciones son el folclore (el Rancho de Ánimas) y los bailes, así como la búsqueda de la realización de actividades tras la jubilación de sus respectivos trabajos. Muchos declaran sentir felicidad, orgullo, cariño o devoción por su labor en el Proyecto, así como no sentir obligaciones a la hora de participar. Hay variedad en cuanto a la motivación de participación en el Proyecto, aunque se destaca la de bailar o cantar; algunos resaltan su papel formando parte de la exposición en los museos: moliendo, haciendo la siembra, explicando la carpintería o el almacén de empaquetado de tomates. Todos muestran la experiencia de sentirse útiles en su participación. Son diversas las aportaciones que destacan el nivel personal, como ganar salud o mantener amistades.

Los entrevistados destacan que todo es importante en el Proyecto, aunque específicamente las relaciones establecidas con los voluntarios y la conservación de los bienes tangibles e intangibles del mismo. La totalidad de los participantes en la en- 
trevista expresan que no cambiarían nada del Proyecto, así que cuando tienen alguna propuesta la proponen en la asamblea, se debate y se busca un consenso para decidir. Todos formulan que les gusta la forma de gestión, así como su deseo de mantener el modelo actual de funcionamiento. De las entrevistas realizadas se deriva que no ha habido conflictos de gravedad, y solo los pequeños desacuerdos entre participantes se solucionan hablando y normalmente de manera rápida. Se consideran un grupo.

Aunque todos los voluntarios entienden que el Proyecto puede crecer con más visitantes y visibilidad, consideran que no se pueden ver desbordados para atender a grandes masas de visitas. Creen que se le puede dar más promoción desde la administración pública. Todos los entrevistados opinan que no se tendría que profesionalizar todo o parte del Proyecto, y que, si esto pasase, dejarían de participar en el mismo. Lo que sí se ha pensado es la creación de una cooperativa que cobre por realizar otros servicios (como servir comidas o vender souvenirs), los ingresos serían para la cooperativa. Todos creen que la entrada a los museos debe seguir siendo gratuita.

Los problemas, aunque no se destaquen, son principalmente la falta de ayudas económicas para realizar el mantenimiento de los museos o para la comida de los animales, así como la pérdida de voluntarios. El mayor reto ha sido el viaje realizado a Cuba en 1993, en el cual unas 80 personas se financiaron el billete realizando diversas actividades de tipo cultural. Todos los entrevistados coinciden que los problemas se solucionan hablando. Los coordinadores del Proyecto juegan un importante papel para la resolución de problemas de diversa gravedad. Los voluntarios entienden que el Proyecto debe mantenerse con la gente que se va incorporando. Las instituciones púbicas tienen la posibilidad de ayudar a mantener el modelo actual, comprando los espacios privados y cediendo la gestión a la asamblea, la propiedad sería municipal. El modelo, aunque está consolidado, se fortalecería de esta manera.

\subsection{Conversaciones informales}

Se deduce de las conversaciones informales realizadas a los responsables de diez establecimientos comerciales de las cercanías del centro de la ciudad de La Aldea de San Nicolás (donde se ubica el PDCLA), que la realización de las diversas actividades que desarrolla el Proyecto repercute de forma positiva en sus negocios. La totalidad de las personas con las que se realizaron estas conversaciones muestra su apoyo al mismo, y declaran que desde su inicio ha sido fructuoso tanto desde un punto de vista social, pero sobre todo económico. Se observa que los beneficios son mayores en cuanto más cerca estén sus negocios al centro del municipio, donde se concentra la mayoría de los museos vivos. 
En cuanto a la sostenibilidad en el tiempo del Proyecto, hay diversidad de opiniones. Aproximadamente la mitad de los comerciantes pone en duda la viabilidad y mantenimiento a largo plazo del Proyecto (10 años como referencia). La principal razón que muestran es la elevada edad de la mayoría de los voluntarios que actualmente participan en los museos vivos, y temen que no pueda ser sostenible a varios años vista. Sin embargo, la otra mitad no pone en duda la sostenibilidad social, que implicaría sostenibilidad económica del Proyecto (incluyendo museos y otras representaciones), consideran que serán otras personas las que asuman responsabilidades, y que por lo tanto seguirán con las actividades que hasta ahora desarrollan. Evidentemente, los que tienen dudas sí manifiestan la esperanza de mantener las visitas al entorno, ya que con ello se benefician económicamente del visitante. Absolutamente todos muestran acuerdo en la necesidad de conceder más ayudas económicas (ya sea a través de instituciones públicas o privadas) al Proyecto Comunitario.

Figura 10. Visitante en el Almacén de empaquetado de tomates

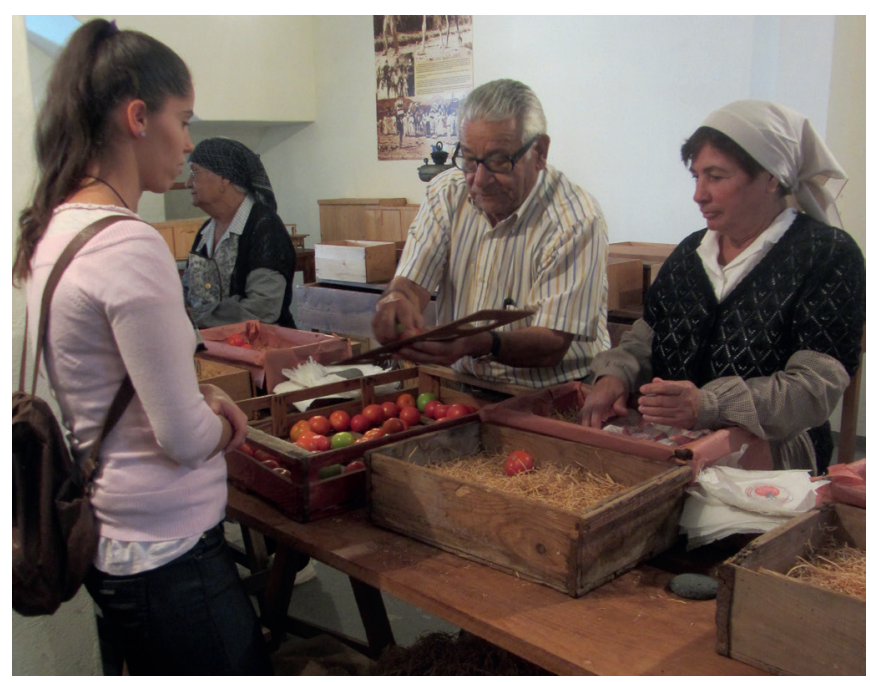

Foto: Héctor Moreno Mendoza (diciembre de 2017).

\section{Discusión}

Los voluntarios del PDCLA piensan que este modelo es el más adecuado para la gestión, haciendo partícipe a más gente, involucrando sobre todo a los jóvenes. La misión (a corto plazo) del Proyecto es seguir creciendo, ya que los implicados entienden que no está todo terminado. Mientras que la visión (la proyección futura) es perpetuar en el tiempo la cultura que generaron las diferentes formas de vida. 
Como conclusiones al caso de estudio que se ha seleccionado, se han determinado tres aspectos, que son generalizables a otros ecomuseos: a) la elevada carga emotiva y de sentimientos, por lo que predomina la palabra sobre los textos. Mientras que en otros museos hay que mantener silencio y evidentemente nada se puede tocar, en este modelo se busca que la gente hable y toque los artefactos todo lo que pueda; b) las personas que están en los espacios museísticos, en ocasiones, son las que han vivido de alguna manera en cada uno de esos lugares, eso hace que lo diferencie de otros; c) el lado altruista de las personas que conforman este museo, lo muestran no solamente presentando lo que hay, sino restaurando, aportando ideas, decorando, animando al visitante a que ellos son los verdaderos protagonistas.

El éxito de un museo no debe medirse como el de una empresa, en términos de beneficio económico para sí mismo o la institución que le patrocina (Barbieri et al., 2017; Evemuseografía, 2017), sino que se basa en la utilidad social que puede aportar a la comunidad de la que es depositario (Brown y Mairesse, 2018). Es poco eficiente realizar una inferencia directa entre éxito y número de visitantes, en tanto que esa cifra tendría que ser ponderada con respecto a la capacidad de convocatoria (conectada con la imagen proyectada) y la influencia en las instituciones, así como con el nivel de satisfacción de sus empleados. Otros indicadores serían el impacto que genera en la calidad de la educación científica de la comunidad y los flujos económicos directa o diferidamente promovidos, incluyendo la capacidad de generar empleos y habilidades empresariales (Beel, 2017). Debido a eso, se requiere el compromiso de todas las partes implicadas en el desarrollo del museo y sus acciones de activación y difusión patrimonial. El conjunto de stakeholders, desde los gestores, a la comunidad local, las empresas y el visitante, como actor principal al que se destinan los esfuerzos de mantenimiento y actualización de la oferta museística, se conforma como núcleo de las posibles estrategias encaminadas a las buenas prácticas (Soren, 2005) en la gobernanza de la institución (Candlin et al., 2020).

\section{Conclusiones}

El presente trabajo se enmarca en un análisis de mayor rango, que trata de constatar no tanto el éxito de los museos, sino de los beneficios comunes que pueden obtenerse por su éxito para las poblaciones implicadas. Potenciar la sensibilidad patrimonial (tanto cultural como ambiental), generar fondos para causas no lucrativas y establecer conciencia de comunidad, en algunos casos de identidad, justifica sobradamente el esfuerzo de la institución para crear amplias redes de impacto social. Es por lo que preocupa establecer instrumentos metodológicos que permitan inferir grados de 
gobernanza y gobernabilidad, determinar el rango y profundidad de sus redes, y la calidad de las relaciones entre los stakeholders. Tal información, generada de manera sistemática, puede contribuir a establecer una relación bidireccional y simbiótica entre el museo y los actores locales, detectando además posibles conflictos de intereses o brechas en la estructura de la red.

La gobernanza de los museos pasa por el valor de lo mostrado, el rigor de lo comunicado, el acercamiento al usuario, la implicación en los entornos locales y un grado aceptable de independencia política y financiera. En destinos turísticos, o cuando el propio museo se constituye como atractivo o complemento motivador de la visita, la literatura de casos parece aconsejar el desarrollo de estrategias que, pasando por el conocimiento, estimen el perfil de sus posibles usuarios-turistas y sus necesidades, por encima del solo interés de comunicación de discursos. Se trata de cumplir con la directriz de transmitir para conservar, y no de banalizar el patrimonio.

Con los resultados obtenidos se puede afirmar la hipótesis planteada al comienzo de esta investigación. Se reconoce como limitación de la investigación presentada y de estas conclusiones la imposibilidad de haber realizado un análisis diacrónico que incluyera el seguimiento de acciones concretas en la red de relaciones. Aun con ello, se considera que la perspectiva expuesta puede contribuir a la generación y fomento de nuevas formas de relación público-privada-comunitaria, estableciendo roles y responsabilidades medibles que apoyen el camino a la sostenibilidad. No parece racional que el museo sea un valor solo para sí mismo y sus proponentes, ni tampoco que el museo sea una suerte de parque temático. El análisis de la operatividad de la gobernanza aplicada al patrimonio muestra diferentes escenarios posibles.

\section{Referencias}

Adán, J. (2010). Cuestiones para la gobernabilidad y planeación de espacios ecoculturales y restricciones para su musealización en Chile. Her\&Mus, Heritage \& Museography, 04, 56-66.

Adie, B. A, y Hall, C. M. (2017). Who visits World Heritage? A comparative analysis of three cultural sites. Journal of Heritage Tourism, 12(1), 67-80.

Agarwal, R., Schwer, B. y Shuman, S. (2016). Structure-function analysis and genetic interactions of the Luc7 subunit of the Saccharomyces cerevisiae U1 snRNP. RNA, 22(9), 1302-1310.

Anderson, J. (1982). Living history: Simulating everyday life in living museums. American Quarterly, 34(3), 290-306.

Ansell, C. y Gash, A. (2008). Collaborative governance in theory and practice. Journal of public administration research and theory, 18(4), 543-571. 
Barbieri, L., Bruno, F. y Muzzupappa, M. (2017). Virtual museum system evaluation through user studies. Journal of Cultural Heritage, 26, 101-108. Recuperado de http:// dx.doi.org/10.1016/j.culher.2017.02.005

Beel, D. E. (2017). The will to empower: reworking governmentality in the museum. Area, 49(4), 460-467. doi: 10.1111/area.12330

Borja, J. y Castells, M. (2006). Local y global. La gestión de las ciudades en la era de la información. México: Taurus.

Brown, K. y Mairesse, F. (2018). The definition of the museum through its social role. Curator: The Museum Journal, 61(4), 525-539.

Bryson, J. M., Crosby, B. C. y Stone, M. M. (2006). The design and implementation of Cross Sector collaborations: Propositions from the literature. Public administration review, 66, 44-55.

Cabildo de Gran Canaria (2018). Conoce Gran Canaria, Recuperado de http://cabildo. grancanaria.com/la-aldea-de-san-nicolas

Candlin, F., Larkin, J., Ballatore, A., y Poulovassilis, A. (2020). The missing museums: accreditation, surveys, and an alternative account of the UK museum sector. Cultural Trends, 29(1), 50-67.

Carbone, F. (2019). Post-multicultural challenges for cultural heritage managers and museums in the age of migrations. Museum Management and Curatorship, 34(1), 2-23.

Catrina, S. (2015). Local Heritage Interpretation by Private "Cultural Agents" from Maramures. Procedia - Social and Behavioral Sciences, 188, 174-180. Recuperado de http://dx.doi.org/10.1016/j.sbspro.2015.03.361

Clarke, A. y Fuller, M. (2010). Collaborative strategic management: Strategy formulation and implementation by multi-organizational cross-sector social partnerships. Journal of Business Ethics, 94(1), 85-101.

Cosmin, I. (2018). Untaping the potential of strategic partnerships with the stakeholders in museums-a managerial approach. Proceedings of the International Conference on Business Excellence. Sciendo 1(12), 446-456.

Crosby, B. C. y Bryson, J. M. (2010). Integrative leadership and the creation and maintenance of cross-sector collaborations. The leadership quarterly, 21(2), 211-230.

Davis, P. (1999). Ecomuseums: a sense of place. Inglaterra: Leicester University Press.

Davis, P. y Corsane, G. (2014). Communities, Heritage and new cultural landscapes. En Roe, M. y Taylor, K. (Eds.), New Cultural Landscapes, (pp. 128-145). Abingdon, UK: Routledge.

Durant, R. F. (2017). Environmental governance reconsidered: challenges, choices, and opportunities. Cambridge: MIT Press.

Eisenhardt, K. M. (2002). Building theories from case study research. En Huberman, A. M. y Miles, M. B. (Ed). The qualitative researcher's companion. London: Sage Publications. 
Elliot, S. (2006). Targets for the arrows of fate: ecomuseology as a rescue mechanism in response to the threatened cultural landscapes of Southeast Turkey. Newcastle, Inglaterra: Newcastle University.

Elsorady, D. A. (2018). The role of stakeholders as a competitive advantage in the formulation of antiquity museum strategies in Egypt. Museum Management and Curatorship, 33(4), 365-38.

Evemuseografía (2017). Museos y medición de éxito. Museos + innovación. Recuperado de https://evemuseografia.com/2016/03/29/museos-y-la-medicion-del-exito/

Freeman, R. E. (1984). Strategic management: A stakeholder approach. Boston: HarperCollins.

Geddes, L. y Shand, R. (2013). Assessing governance and learning lessons. International Journal of Law and Management, 6(55), 401-416.

Gibbs, G. (2012). El análisis de datos cualitativos en Investigación Cualitativa. Madrid: Ediciones Morata.

Girot, P. O. (1998). Co-Manejo de Recursos Naturales y Áreas Protegidas: Teoría y Práctica, CEESP / UICN.

Graham, S., Harris, K. R., Fink-Chorzempa, B. y MacArthur, C. (2003). Primary grade teachers' instructional adaptations for struggling writers: A national survey. Journal of Educational Psychology, 95(2), 279.

Hamel, J., Dufour, S. y Fortin, D. (1993). Case study methods. California: Sage Publications.

Huxham, C. y Vangen, S. (2000). Leadership in the shaping and implementation of collaboration agendas: How things happen in a (not quite) joined-up world. Academy of Management Journal, 43(6), 1159-1175.

Huxham, C. y Vangen, S. (2005). Aiming for collaborative advantage: Challenging the concept of shared vision. Advanced Institute of Management Research Paper, 15.

Idelhadj, I., Rivera Mateos, M. y Rodríguez García, L. (2012). Turismo responsable, espacios rurales y naturales y cooperación para el desarrollo: a propósito de la "Declaración de Tetuán" (Marruecos). PASOS: Revista de Turismo y Patrimonio Cultural, 10(5), 651-664. Recuperado de http://www.pasosonline.org/Publicados/10512/PS0512_19.pdf

Janes, R. R. (2016). Museums without borders. Nueva York: Routledge.

Keast, R., Brown, K. y Mandell, M. (2007). Getting the right mix: Unpacking integration meanings and strategies. International Public Management Journal, 10(1), 9-33.

Klijn, E. H., Steijn, B. y Edelenbos, J. (2010). The impact of network management on outcomes in governance networks. Public Administration, 88(4), 1063-1082.

Lebel, L., Anderies, J., Campbell, B., Folke, C., Hatfield-Dodds, S., Hughes, T. y Wilson, J. (2006). Governance and the capacity to manage resilience in regional social-ecological systems. Ecology and Society, 11(1). 
Legget, J. (2006). Mapping what matters in New Zealand museums. Stakeholders perspectives on museum performance and accountability. (Thesis in management and museums studies) Massey University, New Zealand.

Loach, K., Rowley, J. y Griffiths, J. (2017). Cultural sustainability as a strategy for the survival of museums and libraries. International Journal of Cultural Policy, 23(2), 186-198.

López, J. S. (2003). Norte de Gran Canaria. Guía de Patrimonio Cultural y Turismo Sostenible. Las Palmas de Gran Canaria: Mancomunidad de Ayuntamientos del Norte de Gran Canaria.

Lucchi, E. (2016). Simplified assessment method for environmental and energy quality in museum buildings. Energy and Buildings, 117, 216-229.

Mercer, C. (2005). From indicators to Governance to Mainstream: Tools for Cultural Policy and Citizenship. En Andrew, C., Gattinger, M., Jeannotte, M. S. y Straw, W. (Eds.), Accounting for Culture: Thinking Through Cultural Citizenship (pp. 9-20). Ottawa, Canadá: University of Ottawa Press.

Naumova, A. (2015). "Touching” the Past: Investigating Lived Experiences of Heritage in Living History Museums. International Journal of the Inclusive Museum, 7(3-4), 1-8. doi:10.18848/1835-2014/CGP/v07i3-4/44486..

Newig, J., Challies, E., Jager, N. W., Kochskaemper, E. y Adzersen, A. (2018). The environmental performance of participatory and collaborative governance: a framework of causal mechanisms. Policy Studies Journal, 46(2), 269-297.

Patton, M. Q. (2002). Two decades of developments in qualitative inquiry: A personal, experiential perspective. Qualitative social work, 1(3), 261-283.

Provan, K. G. y Kenis, P. (2008). Modes of network governance: Structure, management, and effectiveness. Journal of Public Administration Research and Theory, 18(2), 229-252.

Red Europea de Ecomuseos (2004). Declaración de Intenciones del Long Net Workshop. Trento, Italia.

Reverté, F. G. y Guix, A. S. (2013). El turismo responsable en España a debate. Consideraciones desde el punto de vista de la producción y del consumo turístico. Investigaciones Turísticas, 5, 60-85.

Sánchez, L. y Suárez, J.P. (2006). Boletín no. 3-4 Rescatar el Patrimonio intangible: el proyecto comunitario de La Aldea de San Nicolás. Patrimonio Histórico. Cabildo de Gran Canaria.

Sánchez, L. G., Suárez, J. P. y Moya, J. (2002). Proyecto comunitario de La Aldea: un compromiso con la cultura popular. Santa Cruz de Tenerife: Gobierno de Canarias. Recuperado de https://bit.ly/2Kk1cvD

Santana, A. (2008). El turismo cultural: ¿un negocio responsable?, Estudios y Perspectivas en Turismo, 17(4), 279 - 294. 
Seitanidi, M. (2008). Adaptive responsibilities: Nonlinear interactions in cross sector social partnerships. Emergence: Complexity \& Organization, 10(3), 51-64.

Selsky, J. W. y Parker, B. (2005). Cross-sector partnerships to address social issues: Challenges to theory and practice. Journal of Management, 31(6), 849-873.

Shaw, C. e Ivens, J. (2002). Building great customer experiences. New York: Palgrave/ Mcmillan.

Simons, H. (2011). El estudio de caso: Teoría y práctica. Madrid: Ediciones Morata.

Soren, B. J. (2005). Best practices in creating quality online experiences for museum users. Museum Management and Curatorship, 20(2), 131-148. doi: https://doi. org/10.1016/j.musmancur.2005.03.001

Souza, R. H. V. D., Solagna, F. y Leal, O. F. (2014). As políticas globais de governança e regulamentação da privacidade na internet. Horizontes Antropológicos, 20(41), 141-172.

Suárez Moreno, F. y Suárez Pérez, A. (2005). Guía del patrimonio etnográfico de Gran Canaria. Las Palmas de Gran Canaria: Cabildo de Gran Canaria.

Taylor, J. K. (2020). Toward a Cooperative Future: Museums and Community. En The Art Museum Redefined (pp. 197-208). Cham: Palgrave Macmillan.

Thomas, G. y James, D. (2006). Reinventing grounded theory: some questions about theory, ground and discovery. British Educational Research Journal. 32(6), 767-795.

Unesco (2011). ¿Qué es el patrimonio cultural inmaterial? Recuperado de https://bit. ly/2XPLOdt.

Vangen, S. y Huxham, C. (2012). The tangled web: Unraveling the principle of common goals in collaborations. Journal of Public Administration Research and Theory, 22(4), 731-760.

Videira, N., Antunes, P. y Santos, R. (2017). Engaging stakeholders in environmental and sustainability decisions with participatory system dynamics modeling. En Gray, S. y Paolisso, M. (Eds.), Environmental modeling with stakeholders (pp. 241-265). Cham: Springer.

Waddock, S. A. y Post, J. E. (1991). Social entrepreneurs and catalytic change. Public administration review, 393-401.

Yacuzzi, E. (2005). El estudio de caso como metodología de investigación: teoría, mecanismos causales, validación. Universidad del CEMA, CEMA Working Papers: Serie Documentos de Trabajo.

Yin, R. K. (2003). Case study research: design and methods. London: Sage Publications.

Zuned A. (2018). Museum Tourism: A Comparative Study on the Royal Museum of Greenwich and the Ironbridge Gorge Museum. En Katsoni V. y Velander K. (Eds.). Innovative Approaches to Tourism and Leisure (67-87). Cham: Springer. 